\title{
PENGARUH KEPRIBADIAN DAN KERJASAMA TIM TERHADAP KINERJA INSTRUKTUR RUMAH SAKIT PENDIDIKAN (TEACHING HOSPITAL) DI KOTA JAKARTA TIMUR
}

\author{
Seny Herna Wanty*
}

\begin{abstract}
The objective of the research is to find out the effect of personality and teamwork on instructor's job performance. This research was conducted at Teaching Hospital in East Jakarta. This research was using a survey method with path analysis applied in testing hypothesis and 67 samples selected by simple random sampling. The research technique is analysis with quantitative research approaches by using causal analysis. The finding of the research are: (1) there is a positive direct effect of personality on job performance; (2) ) there is a positive direct effect of teamwork on job performance; (3) ) there is a positive direct effect of personality on teamwork.
\end{abstract}

Keywords: Job performance, personality, and teamwork.

\section{PENDAHULUAN}

Keberadaan rumah sakit pendidikan (teaching hospital) mempunyai arti yang sangat penting dan strategis dalam rangka meningkatkan mutu pelayanan medik. Seperti sambutan Menteri Kesehatan dalam buku pedoman klasifikasi dan standar rumah sakit pendidikan bahwa rumah sakit pendidikan harus tampil lebih baik dan lebih bermutu karena merupakan etalase mutu pendidikan tenaga kesehatan. Upaya peningkatan mutu pendidikan akan berdampak pada peningkatan mutu pelayanan kesehatan yang pastinya akan dirasakan oleh seluruh masyarakat Indonesia.

Agar tujuan tersebut tercapai, maka penyelenggaraan rumah sakit pendidikan harus memenuhi pedoman klasifikasi dan standar sebagai rumah sakit pendidikan. Standar rumah sakit pendidikan mengacu kepada standar pendidikan kedokteran yang ditetapkan oleh World Federation of Medical Education (WFME), sehingga dalam penyelenggaraannya sebagai rumah sakit pendidikan diharapkan dapat mendukung terlaksananya standar pendidikan tenaga kesehatan, menghasilkan tenaga kesehatan yang berkualitas dan memiliki daya saing serta dapat memberikan perlindungan hukum bagi pemberi pelayanan, penerima pelayanan, peserta didik, dan dosen pembimbing klinik.

Pada awalnya, rumah sakit pemerintah dibangun untuk menyediakan pelayanan kesehatan bagi masyarakat umum terutama masyarakat yang tidak mampu tetapi akhir-akhir ini terjadi perubahan orientasi pemerintah tentang manajemen rumah sakit. Kini rumah sakit pemerintah digalakkan untuk mulai berorientasi ekonomis. Dengan demikian rumah sakit memiliki peran ganda, yaitu

* Pegawai di rumah sakit pendidikan di DKI Jakarta 
tetap melakukan pelayanan publik sekaligus memperoleh penghasilan (laba) atas operasionalisasi pelayanan kesehatan yang diberikan kepada masyarakat.

Bisnis di bidang pelayanan kesehatan, termasuk rumah sakit harus siap menghadapi persaingan global, sebagai konsekuensi dari perubahan yang melanda dunia. Disepakatinya Masyarakat Ekonomi Asean (MEA) 2016, Asean Free Trade Area (AFTA), memiliki arti bahwa pelayanan rumah sakit akan menghadapi persaingan dan kompetisi yang semakin berat untuk dapat terus berkembang mengikuti tuntutan masyarakat maju dan kebutuhan lingkungan kesehatan.

Guna meningkatkan pelayanan yang kompetitif tersebut maka perlu diselenggarakan berbagai upaya untuk meningkatkan kualitas pelayanan. Upaya tersebut didukung antara lain oleh sumber daya tenaga kesehatan yang memadai. Rumah sakit sebagai salah satu jaringan pelayanan kesehatan memiliki peran strategis dalam penyediaan dan pengembangan sumber daya kesehatan yang diharapkan memiliki kompetensi (pengetahuan, keterampilan, sikap dan nilai) yang sesuai dengan perkembangan pengetahuan dan permintaan konsumen.

Rumah sakit, sebagai bagian dari lembaga peyelenggara pelayanan publik, dituntut untuk dapat memberikan pelayanan yang berkualitas, cepat, mudah, terjangkau dan terukur kepada masyarakat dan pihak-pihak terkait. Untuk menyikapi tuntutan-tuntutan tersebut maka diperlukan peningkatan kualitas dan standar pelayanan melalui peningkatan kinerja sumber daya manusia. Peningkatan kinerja sumber daya manusia (karyawan) atau job performance merupakan peningkatan perilaku kerja seseorang berdasarkan standar yang telah ditetapkan dalam waktu tertentu.

Instruktur adalah seseorang yang diangkat dan diberikan tugas oleh institusi pendidikan kesehatan guna memberikan bimbingan kepada mahasiswa yang sedang mengikuti pembelajaran praktek klinik di rumah sakit. Dengan kata lain instruktur diartikan sebagai praktisioner yang berpengalaman, mengajar, menginstruksikan, mensupervisi dan dijadikan model peran oleh mahasiswa. Instruktur juga merupakan orang yang bertanggung jawab untuk memastikan mahasiswa mempelajari dan menerapkan teori, mendapatkan pengalaman, dan mempraktekkan ilmu yang didapatkan dari institusi pendidikannya sehingga menjadi tenaga profesi yang kompeten. Kontribusi instruktur dalam meningkatkan kemampuan mahasiswa saat pembelajaran klinik dimulai dari merencanakan, melaksanakan, dan mengevaluasi pembelajaran praktek klinik mahasiswa. Sehingga untuk meningkatkan mutu pembelajaran praktek klinik mahasiswa maka seorang instruktur klinik harus memiliki kinerja yang baik.

Kinerja instruktur dipengaruhi oleh kepribadian dan kemampuannya bekerja dalam sebuah tim. Karena adanya berbagai profesi dalam lingkup pekerjaannya, maka seorang instruktur klinik diharapkan memiliki kemampuan bekerja dalam sebuah tim. Seorang instruktur juga harus memiliki kepribadian yang baik sehingga bisa melayani pasien sekaligus membimbing mahasiswa dalam pembelajaran klinik. Karena peran gandanya, seorang instruktur kadang menghadapi keluhan yang disampaikan oleh pasien maupun mahasiawa, yang disebabkan antara lain oleh 
minimnya fasilitas yang tersedia untuk melakukan bimbingan, keterbatasan waktu ditengah kesibukan instruktur dalam melakukan tugas profesinya serta rendahnya kompetensi dan kinerja instruktur sehingga proses pembelajaran yang diharapkan oleh mahasiswa tidak tercapai, kurangnya kreativitas dan kepedulian terhadap mahasiswa juga merupakan salah satu kekurangan intruktur.

\section{Kinerja}

Kinerja seorang pegawai/individu berperan penting bagi suatu organisasi karena pada dasarnya kinerja organisasi merupakan kumpulan dari kinerja individu. Kinerja individu merupakan sumbangan bagi tercapainya kinerja bagi setiap fungsi organisasi dan pada gilirannya kinerja fungsi-fungsi organisasi memberi sumbangan terhadap pencapaian kinerja organisasi/perusahaan. Rendahnya kinerja pegawai dalam suatu organisasi dapat mengakibatkan terhambatnya suatu organisasi dalam mencapai tujuannya.

Menurut Jhon B Miner (2005:98), "job performance (calculation of the force on a person to exert a given amount of effort in the performance of a job held)". Kinerja (penghitungan kekuatan seseorang dalam upaya mengerahkan usahanya untuk memberikan kinerja dalam pekerjaannya).

Menurut Jex and Britt (2009: 88), "job performance is a deceptively simple term. At the most general level, it can be defined simply as "all of the behaviors employees engage in while at work." Kinerja adalah istilah yang tampak sederhana. Pada tingkat yang paling umum, dapat didefinisikan sebagai "semua perilaku karyawan yang terjadi pada saat bekerja". Tetapi Jex dan Britt melihat pada kenyataannya karyawan sering terlibat dalam perilaku yang memiliki sedikit atau tidak ada hubungannya sama sekali dengan tugas-tugas pekerjaannya di tempat kerja. Pynes mendeskripsikan job performance sebagai (2004:192), "adaptive job performance is characterized by the ability and willingness to cope with uncertain, new, and rapidly changing conditions on the job. Personnel must adjust to new equipment and procedures, function in changing environments, and continuously learn new skills". Kinerja yang adaptif ditandai dengan kemampuan dan kemauan untuk mengatasi yang tidak pasti, baru, dan perubahan kondisi yang cepat pada pekerjaan. Personil harus menyesuaikan diri dengan peralatan baru dan prosedur, fungsi dalam lingkungan yang berubah dan terus menerus belajar keterampilan baru.

Seiring dengan kemajuan dalam bidang tekhnologi dan informasi maka seorang karyawan harus terus berupaya menambah pengetahuannya agar bisa mengimbangi kemajuan dalam bidang pekerjaannya, hal ini akan berpengaruh terhadap peningkatan kinerjanya. Jadi seorang karyawan harus bisa beradaptasi terhadap perubahan-perubahan yang terjadi di lingkungan pekerjaannya dan perkembangan jaman. Menurut Gibson et al (2011:374), "job performance. The outcomes of jobs that relate to the purposes of the organization such as quality, efficiency, and other criteria of effectiveness." Kinerja. Hasil dari pekerjaan yang berhubungan dengan tujuan organisasi seperti kualitas, efisiensi, dan efektivitas. 
Dari beberapa pendapat yang telah dikemukakan di atas maka dapat disintesiskan bahwa kinerja adalah perilaku individu dalam menyelesaikan tugas yang menjadi tanggung jawabnya untuk memenuhi standar perilaku yang telah ditetapkan dan membuahkan hasil yang diharapkan sesuai dengan tujuan organisasi dengan indikator : 1) kualitas pekerjaan, 2) kuantitas pekerjaan, 3) ketepatan waktu, 4) efektifitas, 5) kemandirian dalam melaksanakan tugas, dan 6) komitmen terhadap tugas.

\section{Kepribadian}

Kepribadian merupakan istilah yang digunakan untuk menggambarkan banyak perasaan dan perilaku. Semakin sering dan konsisten perilaku tersebut timbul dalam berbagai situasi maka akan semakin mendeskripsikan kepribadian individu tersebut. Seperti kepribadian menurut definisi Santrock (2011:132), "personality refers to distinctive thoughts, emotions, and behaviors that characterize the way an individual adapts to the world. Think about yourself for a moment. What is your personality like? Are you outgoing or shy? Considerate or caring? Friendly or hostile? These are some of the characteristics involved in personality". Kepribadian mengacu pada pemikiran yang khas, emosi dan perilaku yang menjadi ciri cara individu menyesuaikan diri dengan dunia. Berpikirlah tentang diri anda sejenak, seperti apa kepribadian anda? Apakah anda senang berteman atau pemalu? Penuh perhatian atau peduli? Bersahabat atau bermusuhan? Ini adalah beberapa karakteristik yang terdapat dalam kepribadian. Hal senada diungkapkan oleh Don Hellriegel et al (2011:165), "personality represents personal characteristics that lead to consistent patterns of behavior. Individuals quite naturally seek to understand these behavioral patterns in interactions with others". Kepribadian merepresentasikan karakteristik pribadi yang mengarah ke pola yang konsisten dari perilaku. Individu secara alamiah berusaha untuk memahami pola-pola perilaku dalam interaksi dengan orang lain.

Colquit et al (2011:296) juga menyatakan bahwa, "conscientiousness people are dependable, organized, reliable, ambitious, hardworking, and preservering. Its difficult, if not impossible, to envision a job in which those traits will not be beneficial. That's not a claim we make about all of the big five, because some job require high level of agreeableness, extraversion, or openness, while others demand low level of those some traits". Orang-orang yang conscientiousness dapat dijadikan tempat bergantung, terorganisasi, bisa diandalkan, ambisius, suka bekerja keras, dan gigih. Adalah sulit bahkan tidak mungkin kita membayangkan suatu pekerjaan dimana sifat-sifat semacam itu tidak akan memberi manfaat. Klaim semacam ini tidak diterapkan pada semua sifat yang ada dalam model lima besar, karena sejumlah pekerjaan menuntut tingkatan agreeableness, extraversion, atau openness yang tinggi. Sedangkan pekerjaan lain menuntut tingkatan yang rendah dari sifat-sifat yang sama. Namun layak untuk dikatakan bahwa conscientiousness memiliki pengaruh besar terhadap kinerja pekerjaan dibandingkan dengan semua lima besar yang lain.

Berdasarkan uraian di atas dapat disintesiskan bahwa kepribadian adalah kombinasi unik dari emosi, pikiran dan pola perilaku individu yang mempengaruhi 
bagaimana individu tersebut bereaksi terhadap situasi dan berinteraksi dengan orang lain dengan indikator: 1) ekstraversasi, 2) stabilitas emosi, 3) kesetujuan, 4) pengaturan diri, 5) keterbukaan terhadap pengalaman.

\section{Kerjasama Tim}

Sebuah organisasi, walaupun memiliki modal besar, dan teknologi yang canggih, tidak mungkin dapat berdayaguna dengan maksimal jika tidak didukung oleh sumber daya manusia yang bagus, yang mempunyai kemampuan dan kompetensi untuk memanfaatkan sumber daya yang ada. Suatu organisasi dalam menjalankan kegiatannya harus didukung oleh sumber daya manusia yaitu anggota-anggota organisasi yang memiliki kompetensi tinggi dengan sikap dan sifat membangun, serta mempunyai daya tanggap tinggi terhadap tujuan organisasi.

Salah satu faktor yang dapat menunjang tercapainya tujuan organisasi adalah kerjasama tim. Kerjasama antar anggota organisasi akan berpengaruh terhadap kinerja yang dihasilkannya, karena dengan melakukan kerjasama tim maka pekerjaan yang dihasilkan akan lebih cepat sehingga membina kerjasama tim yang efektif dalam organisasi adalah suatu keharusan. Kemampuan untuk bekerja secara efektif dalam tim sangat dibutuhkan untuk mencapai tujuan bersama dalam organisasi. Kerjasama tim merupakan bentuk kerjasama beberapa anggota organisasi dengan keterampilan yang saling melengkapi serta berkomitmen untuk mencapai misi yang sudah disepakati bersama dan untuk mencapai tujuan bersama secara efektif dan efisien. Kerjasama tim merupakan peleburan berbagai pribadi yang menjadi satu untuk mencapai tujuan bersama. Pada sebuah tim, beban pekerjaan dibagi sesuai dengan keahlian masing-masing.

Saling mengerti dan mendukung satu sama lain merupakan kunci kesuksesan dari sebuah tim, meskipun sering terjadi perbedaan pemahaman atau perselisihan antar individu, tetapi ketika bekerja dalam tim harus segera disingkirkan terlebih dahulu perbedaan tersebut. Oleh karena itu sangatlah penting untuk menjunjung tinggi kesadaran akan kebersamaan sebagai anggota tim diatas urusan pribadi. Tim yang solid akan menciptakan hasil yang maksimal sebagai tujuan dari tim tersebut.

Kerjasama tim sangat diperlukan guna meningkatkan efiseinsi kerja dalam sebuah organisasi. Jika organisasi tidak memiliki kerjasama yang kuat antara divisi satu dengan divisi lainnya, maka hasil dari kerjanya tidak akan memuaskan dan tidak efisien (tepat waktu). Organisasi terdiri dari berbagai macam individu yang dituntut untuk bekerja dalam rangka mencapai tujuan organisasi. Oleh karena itu, dalam sebuah organisasi harus ada kerjasama tim guna mencapai target yang telah ditetapkan. Schermerhorn (2011:179) mendefinisikan tim sebagai, "a team is a group of people holding themselves collectively accountable for using complimentary skills to achieve a common purpose". Tim adalah sekelompok orang yang secara bersama-sama bertanggung jawab dalam menggunakan keterampilannya untuk saling melengkapi demi mencapai tujuan bersama. 
Schermerhorn (2011:179) juga menjelaskan bahwa, "real teamwork occurs when team members accept and live up to their collective accountability by actively working together so that all their respective skills are best used to achieve important goals". Kerjasama tim terjadi ketika anggota tim menerima dan bertanggung jawab bersama dengan bekerja bersama secara aktif dengan semua keterampilan terbaik mereka masing-masing yang digunakan untuk mencapai tujuan penting. Menurut Jennifer M George and Gareth R Jones (2011:175), "teamwork is emphasized and encouraged by common work areas as is rapid decision making and communication". Kerjasama tim ditekankan dan didorong oleh wilayah kerja umum sebagai pengambilan keputusan dan komunikasi yang cepat. Colquitt et al (2011:375) mendefinisikan tim sebagai berikut, "a team consists of two or more people who work interdependently over some time period to accomplish common goals related to some task oriented purpose". Tim terdiri dari dua orang atau lebih yang saling bekerjasama selama beberapa waktu untuk mencapai tujuan bersama yang tekait dengan tugas-tugas yang telah disepakati.

McShane dan Von Glinow (2008:258) memberikan pengertian, "teams are groups of two or more people who interact and influence each other; and mutually accountable for achieving common goals associates with organizational objectives, and perceive themselves as a social entity with organization". Tim adalah sebuah grup yang terdiri dari dua orang atau lebih yang berinteraksi dan saling mempengaruhi, dan bertanggung jawab bersama untuk mencapai tujuan organisasi yang ditetapkan, dan menganggap diri mereka merupakan kesatuan dalam organisasi.

Dari deskripsi para ahli dapat disintesiskan bahwa kerjasama tim adalah kerjasama antar dua orang atau lebih anggota organisasi yang berinteraksi dan berkolaborasi dalam suatu tim dengan memaksimalkan keterampilan yang dimilikinya untuk mencapai tujuan organisasi dengan indikator 1) komunikasi dalam tim 2) dapat bekerja sama, 3) saling memberi dukungan, 4) tanggung jawab bersama, 5) koordinasi.

\section{METODE}

Metode yang digunakan pada penelitian ini adalah metode survey dengan pendekatan kuantitatif. Penelitian survei yang dimaksud adalah bersifat menjelaskan hubungan atau korelasional kausal yang biasa disebut dengan analisis jalur (path analysis). Penelitian analisis jalur adalah suatu teknik untuk mengestimasi pengaruh seperangkat variabel independen (eksogen) terhadap variabel dependen (endogen) dalam hubungan sebab akibat. Variabel eksogen atau yang disebut juga variabel independen yaitu: kepribadian dan kerjasama tim, serta satu variabel endogen atau disebut juga variabel dependen yaitu kinerja.

Populasi terjangkau dalam penelitian ini adalah seluruh instruktur di rumah sakit pendidikan (Teaching Hospital) di Jakarta Timur dengan jumlah instruktur sebanyak 80 orang. Berdasarkan rumus Slovin dengan menggunakan teknik acak sederhana (Simple Random Sampling). Sehingga diperoleh sampel sebanyak 67 orang instruktur. Pengumpulan data yang digunakan dalam penelitian ini adalah statistika deskriptif dan statistika inferensial. 


\section{HASIL DAN PEMBAHASAN}

\section{Pengaruh Kepribadian terhadap Kinerja}

Dari hasil pengujian hipotesis pertama dapat disimpulkan bahwa terdapat pengaruh langsung positif kepribadian terhadap kinerja dengan nilai koefisien korelasi sebesar 0,532 dan nilai koefisien jalur sebesar 0,393. Ini memberikan makna kepribadian berpengaruh langsung positif terhadap kinerja.

Hasil penelitian ini senada dengan pendapat beberapa ahli diantaranya adalah Luthans, yang mengatakan bahwa salah satu dimensi dari keperibadian yaitu sifat kehati-hatian memiliki hubungan yang erat dengan kinerja, menurut Luthans (2011:132), "there is general agreement that conscientiousness has the strongest positive correlation with the job performance". Ada kesepakatan umum bahwa conscientiousness memiliki hubungan positif yang kuat dengan kinerja. Instruktur dengan kepribadian conscientiousness akan memiliki kinerja yang baik, dimana conscientiousness menunjukan perilaku kehati-hatian seseorang dalam bekerja. Sifat kehati-hatian ini tercermin dari cara kerja instruktur yang disiplin dan terorganisir dalam bekerja. Ketika harus melakukan bimbingan terhadap mahasiswa, instruktur tipe ini akan menjelaskan kondisi permasalahan di ruang praktek dengan teratur dan jelas kepada mahasiswa, hal ini untuk menghindari terjadinya kesalahan dalam penanganan terhadap pasien. Menurut McShane dan Glinow (2008:41), kepribadian berpengaruh terhadap kinerja, "conscientiousness and emotional stability (low neuroticism) stand out as the personality traits that best predict individual performance in almost every job group". Conscientiousness dan stabilitas emosional merupakan ciri kepribadian yang terbaik dalam memprediksi kinerja individu dalam hampir setiap kelompok kerja. Big Five Personality disusun bukan untuk menggolongkan individu ke dalam satu kepribadian tertentu, melainkan untuk menggambarkan sifat-sifat kepribadian yang disadari oleh individu itu sendiri dalam kehidupannya seharihari. Dalam penelitian ini, big five personality tidak diperuntukan bagi perekrutan pegawai, tetapi untuk mengetahui kepribadian instruktur sehingga dapat dicari suatu solusi untuk meningkatkan kinerja instruktur. Berdasarkan kerangka pemikiran di atas, maka terdapat pengaruh langsung positif kepribadian terhadap kinerja seorang instruktur, semakin integral kepribadian seorang instruktur maka semakin baik kinerjanya.

\section{Pengaruh Kerjasama Tim terhadap Kinerja}

Dari hasil pengujian hipotesis kedua dapat disimpulkan bahwa terdapat pengaruh langsung positif kerjasama tim terhadap kinerja dengan nilai koefisien korelasi sebesar 0,524 dan nilai koefisien jalur sebesar 0,380. Ini memberikan makna kepribadian berpengaruh langsung positif terhadap kinerja.

Hasil penelitian ini senada dengan pendapat beberapa ahli diantaranya adalah pendapat Schermerhorn et al (2011:158), “organizations everywhere are using teams and teamwork to improve performance. The catchwords of these new approaches are empowerment, participation, and involvement". Rumah sakit menggunakan tim dan 
kerjasama tim untuk meningkatkan kinerja. Karena adanya berbagai jenis profesi yang harus bekerja bersama dalam satu pelayanan medis, maka kerjasama tim merupakan hal mutlak yang diperlukan dalam mencapai kinerja yang diharapkan. George dan Jones (2011:378) yang mengatakan bahwa kerjasama tim berpengaruh terhadap kinerja dalam suatu organisasi, "thousand of companies now organize their employees into groups and teams to make and sell their goods and services because teamwork can significantly improve employee productivity and efficiency. Whether or not a company succeeds in creating high-performing teams depends crucially on the way managers and supervisors structure and control team member's behaviors". Saat ini rumah sakit mengatur instruktur kedalam suatu tim untuk melakukan pekerjaannya sehari-hari, kerjasama tim secara signifikan dapat meningkatkan kinerja instruktur. Apakah berhasil atau tidak rumah sakit dalam menciptakan kinerja tim yang tinggi sangat tergantung pada kontrol perilaku anggota tim yang dilakukan oleh atasan dan pihak manajer rumah sakit. Memang tidak mudah menghasilkan sebuah tim yang kompak dan solid. Tak hanya efektif, kerjasama tim yang kompak dan solid akan menciptakan suatu pertumbuhan positif dalam organisasi rumah sakit. Berdasarkan kerangka pemikiran di atas, maka terdapat pengaruh langsung positif kerjasama tim terhadap kinerja seorang instruktur, semakin baik kemampuan seorang instruktur dalam kerjasama tim maka semakin baik kinerja yang dapat dicapainya.

\section{Pengaruh Kepribadian terhadap Kerjasama Tim}

Dari hasil pengujian hipotesis ketiga dapat disimpulkan bahwa terdapat pengaruh langsung positif kepribadian terhadap kerjasama tim dengan nilai koefisien korelasi sebesar 0,366 dan nilai koefisien jalur sebesar 0,366. Ini memberikan makna kepribadian berpengaruh langasung positif terhadap kinerja.

Hasil penelitian ini senada dengan pendapat beberapa ahli diantaranya adalah Mcshane dan Glinow (2008:41) yang menyatakan bahwa ada pengaruh kepribadian terhadap kerjasama tim, "many of the concepts that apply to organizations also apply to teamwork.... As a team member, it's important to know how personality differences affect the ability of people to work together." Dalam sebuah tim tentunya terdapat bermacam kepribadian dari berbagai anggota tim. Penting bagi sesama anggota tim untuk saling memahami dan saling mengerti kepribadaian anggota tim lainnya. Dari data yang diperoleh penelitian ini didapat bahwa anggota tim dengan kepribadian extraversion merupakan tipe kepribadian yang paling mudah bekerja dalam kerjasama tim. Kepribadian extraversion yang mudah bergaul, senang berinteraksi dengan orang lain, dan memiliki tingkat sosial yang tinggi menyebabkan instruktur dengan tipe kepribadian ini mudah bekerja dalam kerjasama tim. Menurut McShane dan Glinow (2008:76), "studies report fairly strong associations between personality and several workplace behaviors and outcomes, even when employee ability and other factors are taken into account. Conscientiousness and emotional stability (low neuroticism) stand out as the personality traits that best predict individual performance in almost every job group". Penelitian ini menunjukkan ada hubungan yang kuat antara kepribadian dengan perilaku dan hasil kerja, termasuk 
kemampuan instruktur dan faktor lainnya. Conscientiousness dan emotional stability (low neuroticism) menonjol sebagai ciri kepribadian yang terbaik memprediksi kinerja instruktur dalam hampir setiap kerjasama tim. Berdasarkan kerangka pemikiran di atas, maka terdapat pengaruh langsung positif kepribadian terhadap kerjasama tim seorang instruktur, semakin baik kepribadian seorang instruktur maka semakin baik kemampuannya untuk bekerjasama dalam sebuah tim.

\section{PENUTUP}

Kesimpulan: 1) Kepribadian berpengaruh langsung positif terhadap kinerja. Artinya semakin integral kepribadian yang dimiliki oleh para instruktur mengakibatkan kinerja yang baik dari para instruktur di rumah sakit pendidikan (Teaching Hospital) di kota Jakarta Timur. 2) Kerjasama tim berpengaruh langsung positif terhadap kinerja. Artinya semakin baik kemampuan dalam kerjasama tim seorang instruktur mengakibatkan kinerja yang semakin baik dari para instruktur di rumah sakit pendidikan (Teaching hospital) di kota Jakarta Timur. 3) kepribadian berpengaruh langsung positif terhadap kerjasama tim. Artinya semakin integral kepribadian yang dimiliki oleh seorang instruktur mengakibatkan kemampuan kerjasama tim yang semakin baik dari para instruktur di rumah sakit pendidikan (Teaching Hospital) di kota Jakarta timur.

Saran: 1) Bagi Kepala Instansi Kesehatan pada rumah sakit pendidikan (Teaching Hospital) untuk membantu meningkatkan kinerja instruktur melalui pelatihan kepribadian dan mendorong semangat dan motvasi instruktur untuk dapat bekerjasama dalam tim. Dengan meningkatnya kinerja instruktur diharapkan instruktur bisa membantu mahasiswa dalam melakukan pembelajaran klinis, sehingga dapat menghasilkan tenaga kesehatan yang berkualitas. Hal ini demi terwujudnya harapan pemerintah untuk dapat meningkatkan derajat kesehatan masyarakat Indonesia; 2) Bagi instruktur, agar dapat menemukan potensi yang ada pada dirinya sehingga bisa lebih giat bekerja dan berkreativitas, lebih bertanggung jawab dan memiliki kesadaran mendalam untuk menciptakan kinerja yang baik.

\section{DAFTAR RUJUKAN}

Colquitt, Jason A., Jeffery A. Lepine and Michael J. Wesson. Organizational Behavior. New York: McGraw-Hill, 2011.

George, Jennifer M. Gareth R. Jones, Understanding and Managing Organizatioan behavior. New York: McGraw-Hill 2011.

Griffin, Ricky W. and Gregory Moorhead, Organizational Behavior. Canada: Nelson Education, Ltd, 2012.

Hellriegel, Don \& John W. Slocum, Jr, Organizational Behavior, Thirteenth Edition. South-Western, Cengage Learning, 2011. 
Locke, Edwin A. Handbook of Principles of Organizational behavior, Second Edition. United Kingdom : Wiley \& Son, 2009.

Luthans, Fred. Organizational Behavior: An Evidence-Based-Approach, Twelfth Edition. New York: McGraw-Hill, 2011.

McShane Steven and Marry Von Glinow, Organizational behavior, 4th Edition. New York: McGraw-Hill/Irwin, 2008.

Miner, John B, Organizational Behavior I: Essential Theories of Motivation and Leadership, London: M.E. Sharpe, Inc, 2005.

Pynes, Joan E. Human Resource Management for Public and Nonprofit Organizations, Second Edition. San Francisco: Jossey-Bass, 2004.

R Schermerhorn, John et, al., Organizational Behavior, 11th Edition. New York, John Willey \& Sons, Inc, 2011.

Robbins, Stephen P. and Mary Coulter, Management, 11th Edition. New York: Pearson Education, 2013.

Robbins, Steven and Timothy A. Judge. Organizational Behavior. 15th Edition. New Jersey: Pearson International Education. Inc, 2013. 